\title{
In-situ catalytic upgrading of biomass pyrolysis vapor: Co-feeding with methanol in a multi-zone fixed bed reactor
}

\author{
Masoud Asadieraghi, Wan Mohd Ashri Wan Daud*
}

Department of Chemical Engineering, Faculty of Engineering, University of Malaya, 50603 Kuala Lumpur, Malaysia

\section{A R T I C L E I N F O}

Article history:

Received 6 November 2014

Accepted 27 December 2014

Available online 16 January 2015

\section{Keywords:}

HZSM-5

Biomass

In-situ upgrading

Methanol

Co-feeding

Coke

\section{A B S T R A C T}

The in-situ catalytic upgrading of the biomass pyrolysis vapor and its mixture with methanol were conducted in a fixed bed multi-zone reactor. The steps were comprised; thermally converting the biomass in the pyrolysis reactor, passing its vapor in contact with the HZSM-5 zeolite catalyst in the presence of methanol vapor, and transformation of the resulting upgraded pyrolysis vapor into the liquid product. The biomass pyrolysis and catalytic pyrolysis vapor upgrading were performed at $500^{\circ} \mathrm{C}$. The highly valuable chemicals production was a function of the hydrogen to carbon effective ratio $\left(\mathrm{H} / \mathrm{C}_{\mathrm{eff}}\right)$ of the feed. This ratio was regulated by changing the relative amount of biomass and methanol. More aromatic hydrocarbons ( $50.02 \mathrm{wt} . \%$ ) and less coke deposition on the catalyst (1.3 wt.\%) were yielded from the biomass, when methanol was co-fed to the catalytic pyrolysis process $\left(\mathrm{H} / \mathrm{C}_{\mathrm{eff}}=1.35\right)$. In this contribution, the deposited coke on the catalyst was profoundly investigated. The coke, with high contents of oxo-aromatics and aromatic compounds, was generated by polymerization of biomass lignin derived components activated by catalyst acid sites.

\section{Introduction}

Environmental concerns caused by using fossil fuels, increasing of global energy demand, oil price rising and shortage of petroleum resources motivated the development of alternative energy sources for the production of renewable liquid fuels [1,2]. Lignocellulosic biomass has been considered as a promising alternative energy source, as it is renewable, $\mathrm{CO}_{2}$ neutral, and has the potentia to participate in secure energy supply. Thermal conversion of the biomass can play an important role to produce materials that can replace fossil fuels [3]. Pyrolysis is one of the most important pathways for the biomass conversion into the bio-oil (chemicals and fuels). The bio-oil, a dark brown liquid, is generally acidic and has high oxygen and water content [4].

The presence of the oxygenated compounds caused most of the deficiencies of the bio-oil, such as its high corrosiveness, immiscibility with petroleum fuels, low heating value, and instability under prolonged transportation and storage conditions $[1,4]$. Over the last twenty years, there have been dozens of investigations focused on the biomass and its derived feedstock catalytic conversion with acidic zeolite catalysts, such as Mordenite, Y, Beta and

\footnotetext{
* Corresponding author. Tel.: +60 172907256; fax: +60 10379675371. E-mail addresses: masoud.asadieraghi@gmail.com (M. Asadieraghi), ashri@um. edu.my (W.M.A. Wan Daud).
}

HZSM-5. They were studied as candidate catalysts for the biomass pyrolysis. Among them, HZSM-5 was the most important zeolite investigated and was found to considerably change the composition of the bio-oils by both increasing the aromatic species and producing gasoline like components and simultaneously reducing the amounts of oxygenated compounds through deoxygenation reactions [5,6]. Formation of large amount of coke and consequently rapid zeolite catalyst deactivation is the main problem for the biomass thermal conversion with zeolites.

A parameter named the hydrogen to carbon effective ratio $(\mathrm{H} /$ $\left.C_{\text {eff }}\right)$ has been defined by Chen et al. [7]. This parameter, which is shown in Eq. (1), can be utilized to compare the relative amount of hydrogen available in various feeds and to describe if a feed can be economically converted into hydrocarbons using zeolite catalysts according to the amount of hydrogen, carbon and oxygen in the feed. In Eq. (1), H, O and C are the moles of hydrogen, oxygen and carbon in the feed, respectively.

$$
\mathrm{H} / \mathrm{C}_{\mathrm{eff}}=\frac{\mathrm{H}-2 \mathrm{O}}{\mathrm{C}}
$$

Chen et al. [7] showed that feedstocks with hydrogen to carbon effective ratio $\left(\mathrm{H} / \mathrm{C}_{\text {eff }}\right)$ less than 1 were difficult to upgrade over HZSM-5 catalyst due to its quick deactivation. The $\mathrm{H} / \mathrm{C}_{\text {eff }}$ ratio of petroleum based feedstocks varies from 1 to 2 , whereas that of the biomass feeds are only from 0 to 0.3 . Therefore, the biomass 
contained hydrogen deficient molecules; and approaches for the biomass and its derived feedstocks transformation must consider their $\mathrm{H} / \mathrm{C}_{\text {eff }}$ ratio.

Chang and Silvestri [8] stated that hydrogen deficient oxygenated compounds could be successfully converted on HZSM- 5 zeolite catalyst if co-fed with an adequate amount of hydrogen rich chemicals such as methanol. In the other research, Melligan et al. $[9,10]$ showed major improvement in the biomass pyrolysis vapor by using hydrogen as carrier gas over Ni-HZSM-5 and Ni-MCM-41 catalysts. Ni loading to the catalysts caused acid sites enhancement and consequently increased decarboxylation, dehydration, and cracking reactions. Therefore, the yield of the aromatic hydrocarbons was increased. Recently Zhang et al. [5] showed that the thermal conversion of the biomass derived feedstocks to petrochemicals over zeolite catalysts was a function of the $H / C_{\text {eff }}$ ratio of the feedstock. This suggested that the petrochemicals yield would be enhanced, while it was co-fed with a feedstock owing a high $\mathrm{H} / \mathrm{C}_{\mathrm{eff}}$ ratio.

Methanol has shown to produce high yield of hydrocarbons, when processed over zeolite catalysts $[11,12]$. In addition, it is usually recommended as an appropriate co-processing component due to its high $\mathrm{H} / \mathrm{C}_{\text {eff }}$ ratio of 2 . Therefore, methanol can be co-fed with biomass to enhance the overall hydrogen to carbon effective ratio of the feed. Fig. 1 indicates the overall reaction chemistry of the biomass derived feedstocks cofed with methanol over the HZSM5 catalyst.

The biomass-derived feedstocks first undergo decarbonylation, decarboxylation and dehydration reactions to produce $\mathrm{CO}_{2}, \mathrm{H}_{2} \mathrm{O}$, $\mathrm{CO}$ as well as intermediate oxygenated compounds and homogeneous coke on the catalyst's surface. In the second stage, these intermediate oxygenated compounds diffuse into the zeolite catalyst pores and produce olefins and aromatics as well as heterogeneous coke through a series of oligomerization, dehydration, decarbonylation and decarboxylation reactions. The formation rate of the aromatic compounds is quite slow compared to the pyrolysis reaction. The coke generation, from polymerization of the pyrolysis vapors' oxygenated molecules, is the considerable competing reaction with the aromatic's formation. The aromatic production reactions continue through a hydrogen pool or a common intermediate within the framework of zeolite. Methanol co-feeding with the biomass probably alters the hydrocarbon pool and enhances the aromatics formation rate $[5,13,14]$.
To the best of our knowledge in-situ catalytic pyrolysis vapor upgrading through its co-feeding with methanol over HZSM-5 zeolite catalyst in a fixed bed reactor has not been reported. The objective in the present study is to investigate the in-situ catalytic pyrolysis vapor upgrading of palm kernel shell (PKS) and its mixture with methanol in a fixed bed multi-zone reactor to study the effects of methanol co-feeding on the improvement of valuable hydrocarbons yield. Further, special attentions has been drawn to reduce catalyst deactivation. This study therefore provides critical insights, as to how the aromatics' yield can be enhanced by cofeeding of PKS with methanol that have a high hydrogen to carbon effective ratio.

\section{Materials and methods}

\subsection{Biomass materials}

The palm oil biomass named palm kernel shell (PKS) (Table 1) was obtained from Szetech Engineering Sdn. Bhd. located in Selangor, Malaysia. The sample was crushed using high-speed rotary cutting mill and sieved to desired particle size $(<300 \mu \mathrm{m})$. Then, the sample was dried at $105{ }^{\circ} \mathrm{C}$ for $24 \mathrm{~h}$ and kept in tightly screw cap plastic bottles. The approximate molecular formula of the biomass was $\mathrm{C}_{4.1} \mathrm{H}_{5.5} \mathrm{O}_{2.7}$.

\subsection{Preparation of the catalytic materials}

The catalytic materials used for the in-situ biomass pyrolysis vapor experiments were a crystalline HZSM-5 zeolite (Zeolyst $\mathrm{CBV} 5524 \mathrm{G}, \mathrm{SiO}_{2} / \mathrm{Al}_{2} \mathrm{O}_{3}$ molar ratio $=50$ ). The catalyst was calcined at $550{ }^{\circ} \mathrm{C} / 12 \mathrm{~h} /$ air with heating ramp of $3{ }^{\circ} \mathrm{C} / \mathrm{min}$.

\subsection{X-ray Flouresence (XRF) analysis}

The inorganic contents of the catalyst sample was quantified using X-ray Flouresence (XRF) instrument (PANalytical Axios ${ }^{\mathrm{mAX}}$ ).

\subsection{Scanning electron microscopy (SEM) analysis}

The surface nature of the virgin and regenerated catalysts was investigated by SEM (model FEI QUANTA 450 FEG, operating at a $5 \mathrm{kV}$ accelerating voltage and low vacuum) to characterize the

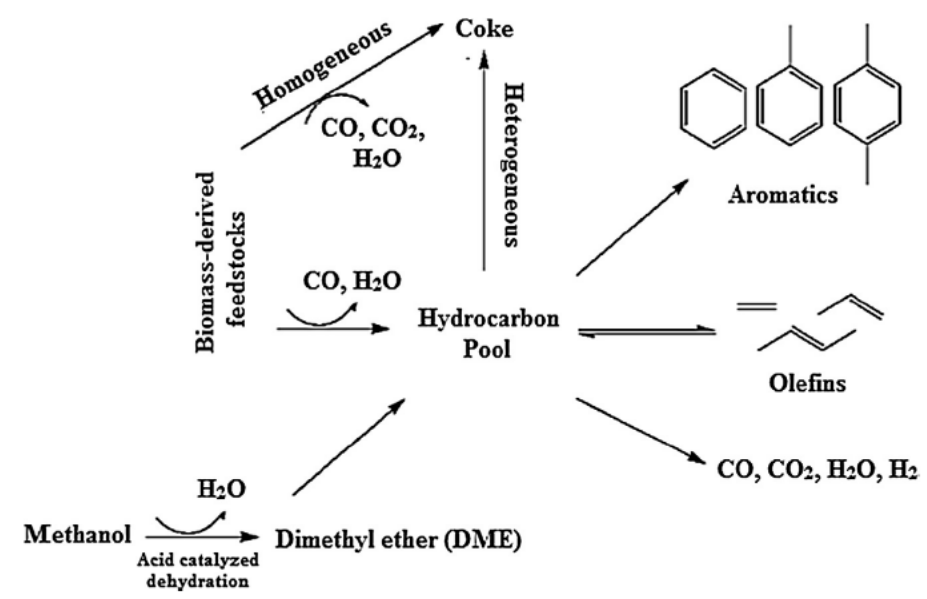

Fig. 1. Overall reaction chemistry for biomass/methanol co-feeding over HZSM-5 zeolite catalyst during pyrolysis/upgrading $[5,13,14]$. 
Table 1

\begin{tabular}{lc} 
Proximate and ultimate analysis of PKS. \\
\hline Analysis items & Values \\
\hline Chemical compositions (wt.\%) & \\
Cellulose & 20.8 \\
Hemicellulose & 22.7 \\
Lignin & 50.7 \\
Proximate analysis (wt.\%) & \\
Moisture & 2.8 \\
Volatile matters & 67.9 \\
Ash & 16.3 \\
Ultimate analysis (wt.\%) & \\
C & 49.05 \\
H & 5.59 \\
$\mathrm{~N}$ & 0.76 \\
$\mathrm{O}^{\mathrm{a}}$ & 44.22 \\
$\mathrm{~S}$ & 0.38 \\
\hline
\end{tabular}

${ }^{\mathrm{a}}$ By difference.

physical structure of the catalysts. Conductive coating was not applied to prepare the samples for SEM analysis. Samples were prepared by their sticking on carbon sheet.

\subsection{Surface area and porosity analysis}

The surface area and pore size of the catalysts samples were measured, using nitrogen $\left(\mathrm{N}_{2}\right)$ adsorption/desorption isotherm at $-196^{\circ} \mathrm{C}$, by a Micrometrics ASAP 2020 gas adsorption analyzer. All the samples were degassed in vacuum at $130{ }^{\circ} \mathrm{C}$ for $24 \mathrm{~h}$ before the measurement. Estimation of pore size diameter was done by Barrett-Joyner-Halenda (BJH) method.

2.6. Temperature-programmed desorption (TPD)

The acid sites of the zeolites catalysts were determined by temperature-programmed desorption of ammonia ( $\left.\mathrm{NH}_{3}-\mathrm{TPD}\right)$ using a Micromeritics Chemisorb 2720. Each sample (ca. $500 \mathrm{mg}$ of finely ground powder) was initially pretreated through heating in $30 \mathrm{ml} / \mathrm{min}$ of pure $\mathrm{He}(99.995 \%)$ from ambient at a rate of $10^{\circ} \mathrm{C}$ min to $600{ }^{\circ} \mathrm{C}$, with a $2 \mathrm{~h}$ hold. Then, the sample temperature was stabilized at $170{ }^{\circ} \mathrm{C}$. After that, the sample was dosed with $30 \mathrm{ml} / \mathrm{min}$ of $10 \% \mathrm{NH}_{3} / \mathrm{He}$ (supplied by Linde) for $30 \mathrm{~min}$. Next, the sample was flushed with $30 \mathrm{ml} / \mathrm{min}$ of He for $30 \mathrm{~min}$ to eliminate weakly bound (physisorbed) $\mathrm{NH}_{3}$ and then, the temperature of the sample was decreased to $50^{\circ} \mathrm{C}$. When a stable baseline was achieved by thermal conductivity detector (TCD), the temperature was then ramped from $50^{\circ} \mathrm{C}$ at a rate of $10^{\circ} \mathrm{C} / \mathrm{min}$ to $600{ }^{\circ} \mathrm{C}$ and was held for $2 \mathrm{~h}$. During this process, the ammonia desorption rate was recorded by $\mathrm{TCD}$.

\section{7. $X$-ray diffraction $(X R D)$}

X-ray powder diffraction (XRD) was performed to verify the crystallinity of the zeolites. The diffraction patterns were monitored on a PANanalytical diffractometer employing $\mathrm{Cu}$ as anode material with $\mathrm{K} \alpha(k=1.54443 \mathrm{~A})$ radiation to generate diffraction patterns from powder crystalline samples at room temperature. The spectra were scanned at a rate of $2.0^{\circ} / \mathrm{min}$ in the range $2 \theta=5-80^{\circ}$.

\subsection{FTIR spectroscopy}

To qualitatively analyze the functional groups of the chemical components available in the raw and upgraded bio-oil, Fourie transform infrared spectroscopy (FTIR; model: BRUKER TENSOR
27) was utilized. The samples were scanned over the range from 600 to $4000 \mathrm{~cm}^{-1}$ with a resolution of $4 \mathrm{~cm}^{-1}$.

\subsection{GC-MS analysis}

For the quantitative measurement and qualitative identification of semi-volatile and volatile organic compounds in the bio-oil, GC/ MS-QP 2010 SHIMADZU, equipped with flame ionization and mass spectrometry detection (GC-FID-MS) was used. A capillary column with length of $30 \mathrm{~m}$ and diameter $0.25 \mathrm{~mm}$ and coated with a 0.25 $\mu \mathrm{m}$ film of DB-5 was used. The GC was equipped with a split injector at $290^{\circ} \mathrm{C}$ with a split ratio of 1:50. Pure helium gas (99.995\%) was employed as carrier gas at flow rate of $1.26 \mathrm{ml} / \mathrm{min}$. The initial temperature of the oven was set to $50{ }^{\circ} \mathrm{C}$ for $5 \mathrm{~min}$ and then raised to $300{ }^{\circ} \mathrm{C}$ at a rate of $10^{\circ} \mathrm{C} \mathrm{min}^{-1}$ and held for $10 \mathrm{~min}$. The NIST (National Institute of Standards and Technology) library was utilized to identify the compounds. Mass spectrometer (MS) operated in the range of $40-1000 \mathrm{~m} / \mathrm{z}$ with ion source temperature of $200{ }^{\circ} \mathrm{C}$ and at an interface temperature of $240^{\circ} \mathrm{C}$.

The bio-oil organic fraction was separated and then diluted with ethyl acetate ( 99.8 wt.\% supplied by R\&M Chemicals) solvent to a dilution factor of 5 and then filtered using a $25 \mu \mathrm{m}$ syringe filter prior to the injection to GC-MS.

\subsection{Coke analysis}

The coke formation on the HZSM- 5 catalyst, during the biomass pyrolysis vapor upgrading and its co-feeding with methanol, was analyzed. The quantitative analysis was carried out by dissolving $1500 \mathrm{mg}$ of the catalyst in $100 \mathrm{ml}$ of $15 \%$ hydrofluoric acid (HF (49 wt.\%) supplied by R\&M Chemicals). Consequently, the extracted coke in HF was dissolved in $80 \mathrm{ml}$ of ethyl acetate. Then, the ethyl acetate fraction was analyzed by GC-MS (QP 2010 SHIMADZU) equipped with DB-5 column. The thermogravimetrictemperature programmed oxidation (TGA-TPO) analysis, using Diamond TGA/DTG (PerkinElmer) instrument, was employed to quantitatively measure the amount of the coke formed on the catalyst. The sample was heated from 30 to $700{ }^{\circ} \mathrm{C}$ at a rate of $10^{\circ} \mathrm{C}$ min under the synthetic air flow at $200 \mathrm{ml} / \mathrm{min}$. Then, the samples were kept at final temperature for $20 \mathrm{~min}$.

The amounts of internal and external coke within the different zeolite catalysts were measured by combining the data from gas adsorption measurements and TGA. The total amount of coke (external + internal) was estimated by TGA analysis. It was assumed that the fresh samples micropore volume reduction (from the gas adsorption measurements) was corresponded to the internal coke amount (assuming a coke density of $1.22 \mathrm{~g} / \mathrm{cm}^{3}$ ). The remaining coke amount (calculated by subtraction) is then assumed to be external [15]

\subsection{Catalysts regeneration}

The partially deactivated zeolites were regenerated in a muffle furnace at $550{ }^{\circ} \mathrm{C}$ with a heating rate of $3{ }^{\circ} \mathrm{C} / \mathrm{min}$ for $12 \mathrm{~h}$ in the presence of air. Thereafter, the temperature was gradually lowered to $35{ }^{\circ} \mathrm{C}$. The regeneration removed most of the deposited coke from the zeolite structure. The surface area, crystalline structure and surface morphology of catalysts were investigated for the regenerated zeolites.

2.12. Biomass fast pyrolysis (catalytic and non-catalytic) experiments

The biomass pyrolysis/upgrading experiments were carried out in a bench scale multi-zone fixed bed tubular reactor (ID $7.5 \mathrm{~cm}$, height $60 \mathrm{~cm}$ ), made of stainless steel (SS) 316L and heated by a two zone furnace controlled by two PID (Proportional-Integral- 


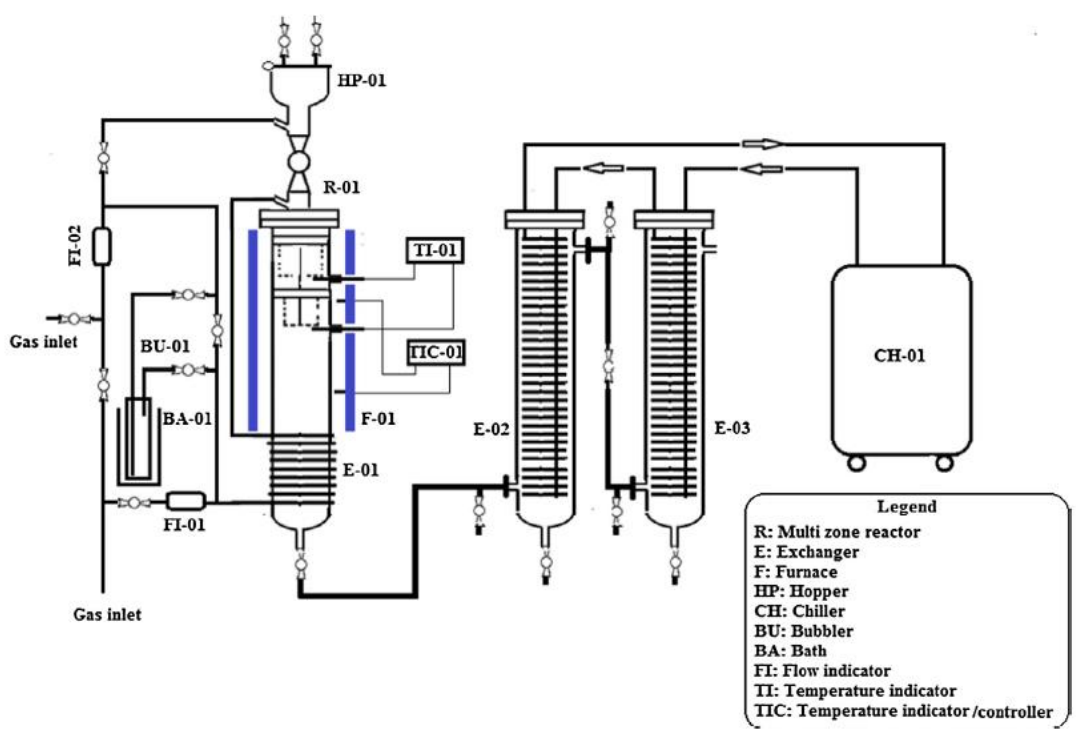

Fig. 2. Schematic of biomass fast pyrolysis/upgrading multi-zone reactor and its accessories.

Differential) controllers. The amount of the biomass used in all experiments was $60 \mathrm{~g}(1 \mathrm{~g} / \mathrm{min})$ and the quantity of the catalyst (in catalytic experiments) was $6 \mathrm{~g}$. In a typical pyrolysis experiment, calcined catalyst was charged to the second zone of the reactor and it was kept at $500^{\circ} \mathrm{C}$ under nitrogen flow $(0.5 \mathrm{l} / \mathrm{min})$ for $60 \mathrm{~min}$. Thereafter, the solid biomass was introduced from the top of the reactor through a hopper, while it was purge by $\mathrm{N}_{2}$, to the first zone of the reactor $\left(\right.$ at $500^{\circ} \mathrm{C}$ ). Two zones of the reactor were cylindrical cups with wire mesh $(\# 400)$ at the bottom sides. The parts material of construction was stainless steel. Two streams of nitrogen gas were introduced to the reactor's top, one $(0.5 \mathrm{l} / \mathrm{min})$ was saturated with methanol ( $99.6 \mathrm{wt} . \%$ supplied by Merck) at different temperatures $\left(40{ }^{\circ} \mathrm{C}, 50^{\circ} \mathrm{C}\right.$ and $\left.55^{\circ} \mathrm{C}\right)$ through a bubble saturator. The bubbler temperature was adjusted by a constant temperature bath. The feeding rate of methanol at various temperatures was estimated from the saturation vapor pressure of the methanol vapor (using Antoine Equation) and the gas flow rate. The other stream was pure nitrogen with the flow of $2 \mathrm{l} / \mathrm{min}$. The mixture of two streams carrying methanol and biomass pyrolysis vapor was driven through a catalyst's bed. Two K-type thermocouples were used to indicate the relevant temperature of pyrolyzer and the fixed bed catalytic reactor. The above mentioned catalytic pyrolysis experiments could be referred as in-situ upgrading of pyrolysis vapors. Furthermore, all the experimental conditions (i.e., low residence time, fast heating of biomass and fast cooling of products) resemble those of the biomass fast pyrolysis (BFP) type of experiments. The bio-oil liquid products were collected using two condensers cooled down by a chilling media at $-5^{\circ} \mathrm{C}$. The pyrolytic vapors, upon their condensation in the condensers, formed the bio-oil. Accumulation of the produced char did not significantly influence bio-oil composition with time due to small particle size of the $\operatorname{PKS}(<300 \mu \mathrm{m})$ and high heating rate of two zone furnace (fast pyrolysis). After each trial, to remove the adsorbed volatile components from the catalyst, it was purged under nitrogen flow $(2 \mathrm{l} / \mathrm{min})$ for $30 \mathrm{~min}$ at $500^{\circ} \mathrm{C}$. The pyrolysis/upgrading setup is shown in Fig. 2.

\section{Results and discussions}

\subsection{Physicochemical characteristics of the zeolite catalyst}

The most important physiochemical characteristics of the HZSM-5zeolite catalyst utilized in the catalytic upgrading of PKS pyrolysis vapor (co-feeding with methanol) are shown in Table 2.

HZSM-5 was chosen as a well-known crystalline zeolite catalyst containing a two dimensional channel like pore system with vertically intersection channels of $\sim 0.55 \mathrm{~nm}$ in diameter [16]. The zeolite surface area in the present investigation was $325 \mathrm{~m}^{2} / \mathrm{g}$ and it was considerably microporous with few textural and structural defects generated the limited meso/macroporosity. The $\mathrm{H}^{+}$form of ZSM-5 zeolite catalyst possessed mostly Brönsted acid sites of high acidic strength. However, during the catalyst's calcination at about $550{ }^{\circ} \mathrm{C}$, for transformation of its $\mathrm{NH}_{4}^{+}$-exchanged form into the $\mathrm{H}^{+}$-form, few acid sites were generated attributed to positively charged tri-coordinated $\mathrm{Si}$ atoms as well as extra-framework octahedrally coordinated aluminum oxyhydroxy species [17].

The acidic properties of HZSM- 5 catalyst was evaluated by $\mathrm{NH}_{3}$ TPD technique and the related profile is indicated in Fig. 3. As shown in this figure, two steps of desorption were observed, conducted to the assumption that at least two types of acid sites existed $[11,14,18]$. The HZSM-5 virgin catalyst contained two acid sites at $\sim 175^{\circ} \mathrm{C}$ (weak acid strength) and $\sim 341{ }^{\circ} \mathrm{C}$ (strong acid strength).

Zhang et al. [19] stated that desorption of the $\mathrm{NH}_{3}$-TPD at temperatures around $250-350{ }^{\circ} \mathrm{C}$ for HZSM-5 could be directly attributed to the density of Brönsted acid sites. Moreover, desorption at lower temperatures might be related to both Lewis and Brönsted acid sites. According to the literature, the weak adsorption sites of ammonia at low temperature were almost inactive in oxygenated compound conversion to hydrocarbons [11]. Therefore, high temperature peak had significant effect on the pyrolysis vapor upgrading. Partially deactivated catalysts showed a decreased high temperature peak position. The shape of high temperature peaks of 
Table 2

Chemical and textural properties of HZSM-5 crystals.

\begin{tabular}{|c|c|c|c|c|c|c|c|c|c|c|}
\hline Sample & $\begin{array}{l}\mathrm{SiO}_{2} / \mathrm{Al}_{2} \mathrm{O}_{3} \\
\text { ratio }^{\mathrm{a}}\end{array}$ & $\begin{array}{l}\text { Crystal length } \\
(\mathrm{nm})^{\mathrm{b}}\end{array}$ & $\begin{array}{l}\text { Crystal width } \\
(\mathrm{nm})^{\mathrm{b}}\end{array}$ & $\begin{array}{l}S_{\text {BET }} \\
\left(\mathrm{m}^{2} \mathrm{~g}^{-1}\right)^{\mathrm{c}}\end{array}$ & $\begin{array}{l}S_{\text {meso }} \\
\left(\mathrm{m}^{2} \mathrm{~g}^{-1}\right)^{\mathrm{d}}\end{array}$ & $\begin{array}{l}S_{\text {BET }} / S_{\text {meso }} \\
\left(\mathrm{m}^{2} \mathrm{~g}^{-1}\right)\end{array}$ & $\begin{array}{l}V_{\text {total }} \\
\left(\mathrm{cm}^{3} \mathrm{~g}^{-1}\right)^{\mathrm{e}}\end{array}$ & $\begin{array}{l}V_{\text {micro }} \\
\left(\mathrm{cm}^{3} \mathrm{~g}^{-1}\right)^{f}\end{array}$ & $\begin{array}{l}V_{\text {meso }} \\
\left(\mathrm{cm}^{3} \mathrm{~g}^{-1}\right)^{\mathrm{g}}\end{array}$ & $\begin{array}{l}D \\
(\mathrm{~nm})^{\mathrm{h}}\end{array}$ \\
\hline $\begin{array}{l}\text { HZSM-5 (used-PKS/ } \\
\text { methanol) }\end{array}$ & & & & 300 & 204 & 1.47 & 0.196 & 0.047 & 0.149 & 10.34 \\
\hline $\begin{array}{l}\text { HZSM-5 } \\
\quad \text { (Regenerated) }\end{array}$ & & & & 319 & 102 & 3.13 & 0.197 & 0.098 & 0.099 & 11.68 \\
\hline
\end{tabular}

a Determined by XRF.

${ }^{b}$ Estimated from SEM images.

c Surface areas were obtained by the BET method using adsorption data in $p / p_{0}$ ranging from 0.05 to 0.25 .

d Measured by $t$-plot method.

e Total pore volumes were estimated from the adsorbed amount at $p / p_{0}=0.995$.

${ }^{\mathrm{f}}$ Measured by $t$-plot method.

g $V_{\text {meso }}=V_{\text {ads } p / p 00-0.99}-V_{\text {micro }}$.

${ }^{\text {h }}$ Average pore width was derived from the adsorption branches of the isotherms by the BJH method.

i $\mathrm{C} / \mathrm{H}_{\mathrm{eff}}=1.3, \mathrm{TOS}=60 \mathrm{~min}$.

j $\mathrm{TOS}=60 \mathrm{~min}$

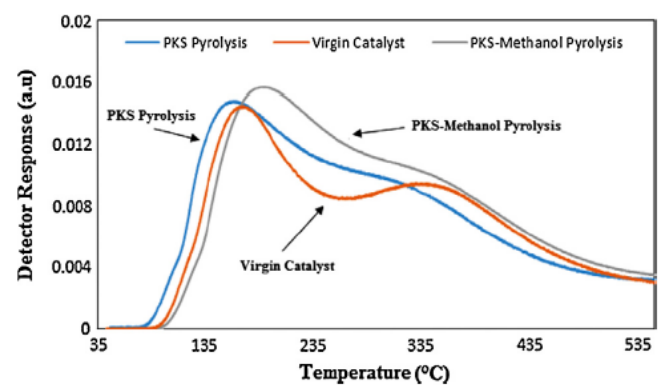

Fig. 3. $\mathrm{NH}_{3}-\mathrm{TPD}$ patterns of HZSM-5 virgin and partially deactivated (TOS $\left.=60 \mathrm{~min}\right)$ catalysts.

partially deactivated catalysts, obtained after PKS and PKS-methanol pyrolysis vapor upgrading, were similar, but the intensity of the latter was slightly stronger than that of the former. This could evidence that methanol co-feeding during PKS pyrolysis vapor upgrading attenuated catalyst deactivation.

XRD diffractograms of the virgin and regenerated catalysts samples are shown in Fig. 4. The XRD patterns were coincident with that of the MFI zeolitic structure. As shown, compared to virgin catalyst, the crystalline structure of the HZSM-5 samples was not changed after regeneration.

Fig. 5 represents SEM photographs of the virgin (a) and regenerated (b) HZSM-5 zeolite catalysts in order to study the effect of regeneration on the catalysts' surface. As can be seen in Fig. 5 , the virgin zeolite was formed by uniform nano-range (100$400 \mathrm{~nm}$ ) crystals.

The SEM photograph of the regenerated HZSM- 5 catalyst $\left(\mathrm{H} / \mathrm{C}_{\mathrm{eff}}=\right.$ 1.3) was very similar to that of the fresh one. This could confirm that catalyst recovered its original textural form after the regeneration process.

\subsection{Products yield}

Among different zeolite catalysts, HZSM-5 has proofed to be very efficient in catalytic pyrolysis of the biomass and also selective toward aromatics formation in the bio-oil [5,20-22]. The yield of the bio-oil, gas and solid products (wt.\%) for the in-situ catalytic pyrolysis process and the co-processing of the biomass pyrolysis

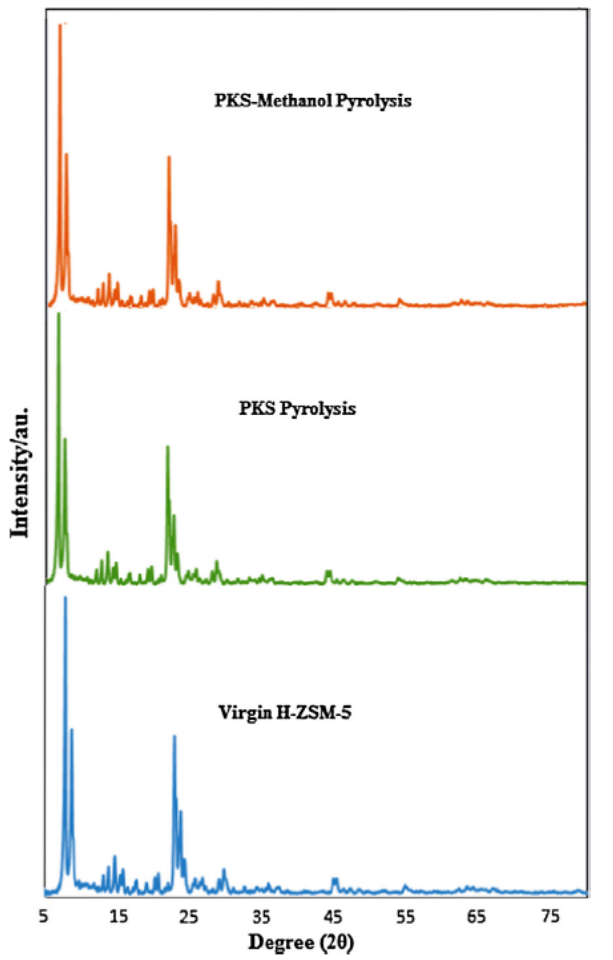

Fig. 4. X-ray diffraction patterns of the virgin and regenerated partially deactivated (during pyrolysis vapor upgrading of PKS and PKS-methanol co-feeding) HZSM-5 catalysts.

vapors and methanol over HZSM-5 catalyst are shown in Table 3 (TOS $=60 \mathrm{~min}$ ). These values were compared to the products yield obtained in non-catalytic pyrolysis. The results of products yield were in agreement with the investigations already performed on the biomass pyrolysis and catalytic upgrading $[17,21,23]$. 

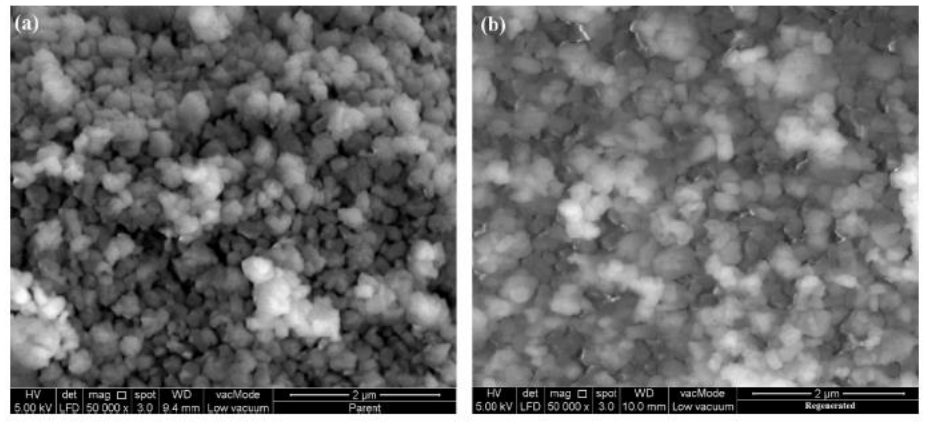

Fig. 5. SEM photographs of the virgin (a) and regenerated (b) HZSM-5 zeolite catalyst.

Table 3

The yield of bio-oil, gas and char (wt.\% on biomass) for the in-situ catalytic pyrolysis process and the co-processing of the biomass pyrolysis vapors and methanol over HZSM-5 zeolite catalyst.

\begin{tabular}{llllllll}
\hline PKS WHSV $\left(\mathrm{h}^{-1}\right)$ & Methanol WHSV $\left(\mathrm{h}^{-1}\right)$ & PKS/methanol ratio $(\mathrm{wt} . \%)$ & $\mathrm{H} / \mathrm{C}_{\text {eff }}$ & Bio-oil (wt.\%) & Gas (wt.\%) & Char (wt.\%) & Water content (wt.\% in bio-oil) \\
\hline 10 & 0 & $100 / 0$ & 0.004 & 26.6 & 39.1 & 34.3 & 68 \\
10 & 6 & $62.5 / 37.5$ & 0.631 & 48 & 22 & 30 & 35.12 \\
10 & 15.6 & $39 / 61$ & 1.09 & 45.2 & 41.1 & 13.7 & 28.24 \\
10 & 27 & $27 / 73$ & 1.35 & 42.5 & 47.8 & 9.6 & 20.9 \\
0 & 18.2 & 2 & 34.9 & 65.1 & 0 & 14.7 \\
Non-catalytic pyrolysis & $0 / 100$ & 0.004 & 48.35 & 17.55 & 34.1 & 57 \\
\hline
\end{tabular}

The highest yield of the liquid bio-oil (48.35 wt.\%) was achieved in non-catalytic runs. The use of zeolite catalyst decreased the biooil yield and increased the gaseous products and water yield. This was caused by different hydrocarbon conversion reactions comprising; cracking, cyclization/aromatization and dehydrogenation, which were mostly catalyzed by the Brönsted acid sites of zeolite $[1,24]$. Water yield enhancement was attributed to increased dehydration of oxygenated compounds on the zeolite catalyst acid sites [17]. Since the catalyst bed and biomass were not in contact, the presence of the catalyst did not affect the decomposition of the solid biomass feed. Hence, the amount of char could be considered constant for all trials and equal to the yield of solid products of the non-catalytic experiments ( $34.1 \mathrm{wt} . \%$ on average). Production of non-condensable gases enhanced in the presence of catalysts as compared to the non-catalytic tests.

The bio-oil yield was slightly decreased from 48 wt.\% to 42.6 wt.\%, when the methanol WHSV was increased from 6 to $27 \mathrm{~h}^{-1}$. This result might be attributed to alternating of the hydrocarbon pool toward production of more gaseous products like olefins. The bio-oil yields produced from biomass/methanol catalytic insitu pyrolysis/upgrading were higher than the yield predicted for each individual methanol and biomass catalytic conversion. The presence of methanol probably promoted the oxygen removal from the biomass pyrolysis/methanol vapors as water. This was already observed by Chantal et al. [25] and Chen et al. [7]. On the other hand, according to the literature [26], the presence of methanol could enhance the production of a large amount of $\mathrm{CO}$. Then, the formed water in the presence of $\mathrm{CO}$ could probably contribute to water gas shift reaction to yield $\mathrm{H}_{2}$ and $\mathrm{CO}_{2}$. This possibly reduced the amount of water content in the produced bio-oil, as the addition of methanol was increased.

\subsection{Bio-oil chemical composition}

3.3.1. Quantitative analysis using GC-MS

The composition of the bio-oils' organic fraction (measured by GC-MS analysis) is shown in Table 4. Literature studies showed different bio-oil organic compounds have been classified into 13 groups; aliphatic hydrocarbons, aromatic hydrocarbons, furans, phenols, acids, alcohols, esters, ethers, aldehydes, ketones, sugars, nitrogen containing compounds and polycyclic aromatic hydrocarbons (PAHs). Among the said compounds, desirables were aromatic hydrocarbons, aliphatic hydrocarbons and alcohols, which were used for biofuels production, while furans and phenols were considered as high added value chemicals. On the other hand, carbonyls, acids, polycyclic aromatic hydrocarbons (PAHs) and heavier oxygenates were regarded as undesirables. Aldehydes and ketones components caused instability of the bio-oil during transportation, while the bio-oils with high acid contents were corrosive and practically difficult to be introduced into engines as fuel. On the other hand, esters and ethers were considered as the oxygenate components, which reduced the heating value of the bio-oil $[17,20,21]$.

As can be seen in Table 4, the bio-oil produced through non-catalytic pyrolysis (without upgrading) was rich in phenolic compounds, but had low content of ketones and acids. Also, some compounds like aromatic, aliphatic hydrocarbons and alcohols were identified in very low concentrations. High phenolic compounds available in the bio-oil could be resulted from high lignin content of PKS biomass (50.7 wt.\%). Accordingly, the bio-oil produced through thermal pyrolysis of the biomass was considered as a low quality product.

As shown in Table 4, catalytic upgrading of the biomass pyrolysis vapor, especially in the case of its co-feeding with methanol, was very efficient in producing the bio-oils having desirable components. HZSM-5 catalyst resulted in the production of different kinds of aromatics. A significant increase of aromatics was seen with methanol WHSV increasing. This was possibly due to the cyclization and oligomerization of light components over acid sites of HZSM-5 catalyst. It was in consistent with the data reported in the literature $[13,17]$. In contrast, the increasing amount of methanol co-fed to the reactor caused diminution of the phenol concentration in the product possibly attributed to the hydrocarbon pool alternation. About undesirable components, carboxylic acids and

Link to Full-Text Articles :

http://www.sciencedirect.com/science/article/pii/S0196890414011212 